\title{
Prenatal diagnosis of cri-du-chat syndrome by SNP array: report of twelve cases and review of the literature
}

\author{
Jiasun Su', Huayu Fu², Bobo Xie', Weiliang Lu', Wei Li', Yuan Wei', Qiang Zhang ${ }^{1}$, Shengkai Wei', Qiuli Chen',
} Yingchi Lu', Tingting Jiang ${ }^{1}$, Jingsi Luo ${ }^{1 *}$ and Zailong Qin ${ }^{1 *}$

\begin{abstract}
Background: Cri-du-chat syndrome (CdCS; OMIM\#123450) is a classic contiguous gene syndrome caused by chromosome $5 p$ terminal deletion (5p-), which characterized by a high-pitched cat-like cry, developmental delay, severe psychomotor, mental retardation, and dysmorphic features in infancy. Prenatal diagnosis of CdCS is difficult due to the non-specific ultrasound features. And reports using array analysis are rare. This study presented the first retrospective analysis of prenatal series of CdCS fetuses diagnosed by single nucleotide polymorphism (SNP) array in China.

Case presentation: A total of 35,233 pregnant women were enrolled from Jan 2014 to April 2019 in our center, there are twelve $5 p$ - cases with abnormal sonographic signs revealed by SNP array, giving an incidence of $0.034 \%(12 / 35,233)$. Clinical information and molecular basis included: maternal demographics, indications for invasive testing, sonographic findings and SNP array results. Among all the 5p- cases revealed, nine cases were diagnosed by both karyotyping and SNP array, three cases were detected only by SNP array. Half of our cases (6/12) had an isolated $5 p$ terminal deletion, which sizes ranged from $9.0 \mathrm{Mb}$ to $30 \mathrm{Mb}$. The other half of cases (6/12) characterized by unbalanced translocation, with sex ratio 7:5 (female: male), when combine the clinical features observed from this study and available literature, the most frequent anomaly observed in prenatal ultrasound examination of CdCS was cerebral abnormalities, accounted for $44.4 \%(16 / 36)$ of the existing cases. Features that are less consistent included: choroid plexus cyst $(13.8 \%, 5 / 36)$, single umbilical artery $(13.3 \%, 4 / 30)$, ventricular septal defect $(11.1 \%, 4 / 36)$, hydrops fetalis $(8.3 \%, 3 / 36)$, ascites $(8.3 \%, 3 / 36)$, increased NT/NF $(8.3 \%, 3 / 36)$, absent/severely hypoplastic nasal bone $(5.5 \%, 2 / 36)$, in order.

Conclusion: Prenatal findings such as cerebral abnormalities, absent/hypoplastic nasal bone, hydrops fetalis, ascites or encephalocele may act as suggestive signs of CdCS or other microdeletion/duplication syndromes. Combining typical karyotyping with chromosomal microarray analysis (CMA) is a definitive method for a precise diagnosis of CdCS and provides more accurate results in order to offer genetic counseling to families which need to deal with cryptic aberrations.
\end{abstract}

Keywords: Cri-du-chat syndrome, Prenatal diagnosis, SNP microarray, Ultrasound findings

\section{Background}

Cri-du-chat syndrome (CdCS; OMIM\#123450) is a wellknown contiguous gene syndrome caused by chromosome $5 \mathrm{p}$ terminal deletion, first reported by Lejeune et al. in 1963 [1]. The prevalence of CdCS in postnatal was reported as 1 in 15,000 to 1 in 50,000 worldwide

\footnotetext{
*Correspondence: Luojingsi0815@126.com; qinzailong@hotmail.com 'Department of Genetic and Metabolic Central Laboratory, Guangxi Maternal and Child Health Hospital, Guangxi Birth Defects Prevention and Control Institute, No.59, Xiangzhu Road, Nanning, China

Full list of author information is available at the end of the article
}

and the female to male ratio was estimated approximately 1.3:1 [2, 3]. Clinical features of CdCS patients in postnatal were characterized a high-pitched cat-like cry, developmental delay, severe psychomotor and mental retardation, dysmorphic features including microcephaly, hypertelorism, epicanthal folds, broad nasal bridge, short neck and micrognathia, other structural anomaly may include limbs abnormalities, scoliosis, brain hypoplasia or agenesis, cardiovascular defect, renal abnormalities and genitourinary anomalies $[4,5]$.

(c) The Author(s). 2019 Open Access This article is distributed under the terms of the Creative Commons Attribution 4.0 International License (http://creativecommons.org/licenses/by/4.0/), which permits unrestricted use, distribution, and reproduction in any medium, provided you give appropriate credit to the original author(s) and the source, provide a link to the Creative Commons license, and indicate if changes were made. The Creative Commons Public Domain Dedication waiver (http://creativecommons.org/publicdomain/zero/1.0/) applies to the data made available in this article, unless otherwise stated. 
Most of the CdCS cases were caused by a de novo $5 p$ interstitial or terminal deletion, which sizes ranged from $560 \mathrm{~kb}$ to $40 \mathrm{Mb}[6,7]$. In fact, approximately $80-90 \%$ of these cases were paternal in origin and $10-15 \%$ were resulted from an unbalanced parental translocations [4]. Other rare complex conditions include 5p-mosaicism $(1.4 \%)$, inversions $(0.5 \%)$, and ring chromosomes $(0.5 \%)$ $[2,8]$.

Several critical regions contributed the specific phenotype of CdCS had been proposed, however, no common recurring breakpoint have been identified on the correlation between deletion size and severity of clinical features. In the terminal $5 p$ region, a variety of genes have been suspicious to be the cause of this disorder [2] .

In current publications, no specific prenatal ultrasound signs related with CdCS had been proposed since few reports of prenatal diagnosis of CdCS had been published. Presentations such as increased nuchal translucency (NT), prominent glabella, micrognathia, short philtrum, cleft lip/palate, cystic cerebral lesions, abnormal nasal bone or renal hypoplasia and isolated ascites were previously reported in cases of CdCS [9-22]. As CMA is being widely utilized in both postnatal and prenatal diagnosis, the specific prenatal ultrasound signs of CdCS could probably be refined. Herein, we reported the first retrospective analysis of prenatal series of CdCS fetuses by presenting 12 prenatal $5 \mathrm{p}$ - cases detected by SNPmicroarray in China, we evaluated the deletion coordinates through reviewing the literature and attempted to define the fetal sonographic features for warranting diagnosis of CdCS.

\section{Case presentation}

\section{Subjects}

Between January 2014 and April 2019, A total of 35,233 pregnant women were referred to our center to perform invasive prenatal diagnosis for abnormalities based on fetal ultrasound anatomy scans or maternal serum screening. Fetal ultrasound anatomy scans were routinely performed for pregnant women by senior sonographers using GE E8 ultrasound machines (General Electric Healthcare, US). The indication included: fetus with ultrasound abnormalities (intrauterine growth restriction, increased NT thickness, cleft lip/palate, cystic cerebral lesions, abnormal nasal bone or renal hypoplasia, etc.), positive maternal serum screening test or NIPT high risk for aneuploidy, etc. This was a retrospective study and approved by the Medical Ethics Committee of the Guangxi Maternal and Child Health Hospital and written consent from the parents.

\section{Molecular and cytogenetic detection}

Chorionic villi sampling, amniocentesis or cordocentesis was performed under ultrasound guidance after informed consent. Genomic DNA was extracted using QIAamp DNA Blood Mini Kit (Qiagen, Germany) according to the manufacturer's protocol. Single-nucleotide polymorphism (SNP) microarray testing was performed using Illumina HumanCytoSNP-12 v2.1 BeadChip (Illumina, USA) and the copy number variation positions were shown according to the human Feb. 2009 (GRCh37/hg19) assembly. The laboratory policy at the time of testing was not to report well established polymorphisms, CNVs that do not contain genes and categorized as benign or likely benign base on the ACMG guideline [23]. Karyotyping was performed for the available samples according to the standard procedure as described previously [24].

\section{Results}

In total, 12 prenatal cases with $5 \mathrm{p}$ terminal deletion were detected in our cohort by SNP array, the median maternal age was $29(21-43)$ years and the median gestational age at prenatal diagnosis was 20.5 (13-29) weeks. Full descriptions of these cases were list in Table 1. Cases 16 with pure 5p terminal deletion, case 7-12 with additional pathogenic chromosome abnormalities, two cases (case 7,10$)$ were referred to the hospital at the first trimester because of an increased NT, the indication of case 1 and case 12 were abnormal NIPT finding for high risk of 5p- and trisomy 18, respectively. In total, 10 cases were identified as $5 \mathrm{p}$ - syndrome due to abnormal ultrasound findings at second trimester. Karyotyping results were available of nine cases (case 1-6, 10-12), all the parents were determined to terminate the pregnancy by considering the poor prognosis, only three cases (case 5 , $6,10)$ preformed parental chromosome analysis. Detailed size and the coordinates of the pure $5 p$ terminal deletions were shown in Fig. 1. Table 2 summarized the ultrasound signs of the prenatal $\mathrm{CdCS}$ cases with pure $5 p$ terminal deletion from the literatures including the twelve cases in our cohort.

\section{Discussion and conclusion}

In the current study, we provided a largest series in prenatal CdCS cases detected by SNP array in China. The incidence of CdCS in our cohort was around $0.034 \%$ $(12 / 35,233)$, much higher than the previously reported incidence of $1 / 50,000-1 / 15,000$ in live births [25]. According to our retrospective analysis, $6 / 12(50 \%)$ of our cases had an isolated $5 \mathrm{p}$ terminal deletion, the proportion $(54.5 \%)$ was lower than that $(62.5 \%)$ reported by Han et al. in eight prenatal cases [20] and greater than that (20\%) reported by L. Mark et al. [22]. 6/12(50\%) of cases characterized by unbalanced translocation, the sex ratio of our CdCS cases was 7/5 (female/male), consistent with the rate of postnatal series by Nguyen, J. M.et al. [2]. 
Table 1 Detailed clinical information of our twelve cases with $5 p$ - syndrome

\begin{tabular}{|c|c|c|c|c|c|c|}
\hline Index & $\begin{array}{l}\text { Maternal } \\
\text { age (years) }\end{array}$ & $\begin{array}{l}\text { Gestation } \\
(w+d)\end{array}$ & G-band & Snp array results & Ultrasound finding & Inheritance \\
\hline 1 & 26 & $23+1$ & 46,XX,del(5)(p13) & $\begin{array}{l}\text { arr [hg19] 5p15.33p13.3 } \\
(38,139-30,536,972) \times 1\end{array}$ & $\begin{array}{l}\text { (NIPT at } 13 \text { weeks: high risk for } 5 \mathrm{p}-\text { ), } \\
\text { Cerebellar hypoplasia }\end{array}$ & \\
\hline 2 & 27 & $24+2$ & $46, X Y$,del(5)(p14) & $\begin{array}{l}\text { arr [hg19] 5p15.33p14.3 } \\
(464,153-23,132,422) \times 1\end{array}$ & Dysgenesis of the cerebellar vermis & \\
\hline 3 & 43 & $16+6$ & $46, X Y$, del(5)(p15) & $\begin{array}{l}\text { arr [hg19] 5p15.33p15.1 } \\
(38,139-17,981,307) \times 1\end{array}$ & Choroid plexus cyst & \\
\hline 4 & 26 & 22 & $46, X X$,del(5)(p15) & $\begin{array}{l}\text { arr [hg19] 5p15.33p15.31 } \\
(38,139-9,782,775) \times 1\end{array}$ & $\begin{array}{l}\text { Abnormal maternal serum } \\
\text { screening (increased } \beta-\mathrm{HCG} \text { ) }\end{array}$ & \\
\hline 5 & 30 & $22+6$ & $46, X X$,del(5)(p14) & $\begin{array}{l}\text { arr [hg19] 5p15.33p14.3 } \\
(38,139-19,508,190) \times 1\end{array}$ & $\begin{array}{l}\text { Cystic adenomatoid } \\
\text { malformation of the lung }\end{array}$ & de novo \\
\hline 6 & 31 & $21+1$ & $46, X X$,del(5)(p14) & $\begin{array}{l}\text { arr [hg19] 5p14.3p15.33 } \\
(1,151,161-20,687,905) \times 1\end{array}$ & $\mathrm{NF}: 6.8 \mathrm{~mm}$ & De novo \\
\hline 7 & 35 & $13+2$ & NA & $\begin{array}{l}\text { arr [hg19] 5p15.33p14.3 } \\
(38,139-22,612,407) \times 1,13 q 31.2 q 34 \\
(89,736,965-115,106,996) \times 3\end{array}$ & Hydrops fetalis, NT:8.7 mm & \\
\hline 8 & 27 & $29+0$ & NA & $\begin{array}{l}\text { arr [hg19] 5p15.33p15.1 } \\
(354,051-17,484,038) \times 1,5 q 34 q \text { 35.3 } \\
(165,731,079-180,705,539) \times 3\end{array}$ & $\begin{array}{l}\text { VSD, NF: } 9 \mathrm{~mm} \text {, abnormality } \\
\text { of lateral ventricle }\end{array}$ & \\
\hline 9 & 37 & $23+5$ & NA & $\begin{array}{l}\text { arr [hg19] 5p15.33p15.1 } \\
(560,476-17,910,453) \times 1,8 q 24.12 q 24.3 \\
(119,864,143-146,293,086) \times 3\end{array}$ & Cerebellar hypoplasia & \\
\hline 10 & 21 & $14+5$ & $\begin{array}{l}46, X X, \operatorname{der}(5) t(5 ; \\
18)(p 15.2 ; q 11.2)\end{array}$ & $\begin{array}{l}\text { arr [hg19] 5p15.33p15.2 } \\
(38,139-10,702,034) \times 1,18 q 11.2 q 23 \\
(19,178,726-78,014,582) \times 3\end{array}$ & $\begin{array}{l}\mathrm{NT}: 5.5 \mathrm{~mm} \text {, abnormal heart valve } \\
\text { morphology, absent of the nasal bone }\end{array}$ & $\begin{array}{l}\text { paternal 46,XY, } \\
\mathrm{t}(5,18)(\mathrm{p} 15.1, \mathrm{q} 11.2)\end{array}$ \\
\hline 11 & 27 & 18 & $\begin{array}{l}\text { 46,XY, der(5)t(5; } \\
\text { 7)(p15;q21) }\end{array}$ & $\begin{array}{l}\text { arr [hg19] 5p15.33p15.2 } \\
(38,139-12,392,815) \times 1,7 q 21.11 q 36.3 \\
(83,599,335-159,119,486) \times 3\end{array}$ & $\begin{array}{l}\text { SUA, DLV, talipes equinovarus, } \\
\text { abnormality of the cerebral ventricles }\end{array}$ & \\
\hline 12 & 26 & $21+2$ & $\begin{array}{l}46, X X, \operatorname{der}(5) t(5 \\
18)(p 15.2, q 12.3)\end{array}$ & $\begin{array}{l}\text { arr [hg19] 5p15.33p15.2 } \\
(560,476-14,855,659) \times 1,18 q 12.3 q 23 \\
(43,354,452-78,014,582) \times 3\end{array}$ & $\begin{array}{l}\text { CLP, VSD, NF: } 6.5 \text { mm, } \\
\text { (NIPT: high risk for T18) }\end{array}$ & \\
\hline
\end{tabular}

$w$ Weeks, $d$ Days, NA Not analysis, NT/NF Nuchal translucency/nuchal fold thickness, VSD Ventricular septal defect, SUA Single umbilical artery, DLV Dilation of lateral ventricles, CLP Cleft lip and palate, $\beta$-HCG Beta-human chorionic gonadotropin.

Prenatal CdCS cases were difficult to be found in first trimester screening (FTS). Less than 50 isolate $5 p$ deletion prenatal cases had been reported since Lejeune et al. described the first 5p- syndrome cases in 1963 [1]. Though abnormal level of serum human chorionic gonadotrophin ( $\beta$-HCG) as well as PAPP-A presented in some of CdCS cases $(22.2 \%, 8 / 36)$ similar to our case 4 [10], the association between the abnormal FTS markers and CdCS were yet to be established. NIPT has rapidly become a part of the standard prenatal care for aneuploidy screening for high-risk pregnancies in our region. Case 1 was screening with CdCS using NIPT with high risk for a large chromosome $5 p$ deletion at 13 weeks. At 23 weeks, the fetus presented cerebellar hypoplasia and amniocentesis SNP array revealed a $29.8 \mathrm{Mb}$ deletion of 5 15.33p13.3. Case 12 indicated a high risk for trisomy 18 by NIPT, fetus ultrasound feature included cleft lip and palate, ventricular septal defect, and increased NF were found at 21 weeks, consistent with the features of trisomy 18. SNP array revealed a $35 \mathrm{Mb}$ duplication at $18 \mathrm{q} 12.3 \mathrm{q} 23$ and a $9.8 \mathrm{Mb}$ deletion at 5p15.33p15.2. We believe that NIPT method would be one very promising screening tool for CdCS in FTS [26], however, due to the low prevalence of CdCS in the population, clinical application of NIPT on CdCS was limited by a low positive predictive values [26-28] .

Abnormal prenatal findings associated with pure 5psyndrome were summarized in Table 2 . Collectively, 13 cases $(16 / 36,44.4 \%)$ were described involving the cerebral abnormalities. Other recurrent phenotypes included: Choroid plexus cyst in 5 patients (13.8\%), Single umbilical artery in 4 patients (11.1\%), ventricular septal defect in 3 cases $(8.3 \%)$, hydrops fetalis in 3 cases $(8.3 \%)$, ascites in 3 cases $(8.3 \%)$, increased NT/NF in 3 cases $(8.3 \%)$, absent/severely hypoplastic nasal bone in 2 cases (5.5\%), abnormal serum markers (hCG, PAPP-A) in 6 cases (22.2\%). Three cases carried out chromosomal analysis for advanced maternal age with $5 \mathrm{p}$ - without abnormal US finding, one case with IUGR and one case with encephalocele. Simmons et al. proposed that deletion of 5 p15.2 was responsible for abnormal cerebral development [29], in our series, $41.6 \%$ (5/12) of cases involving 


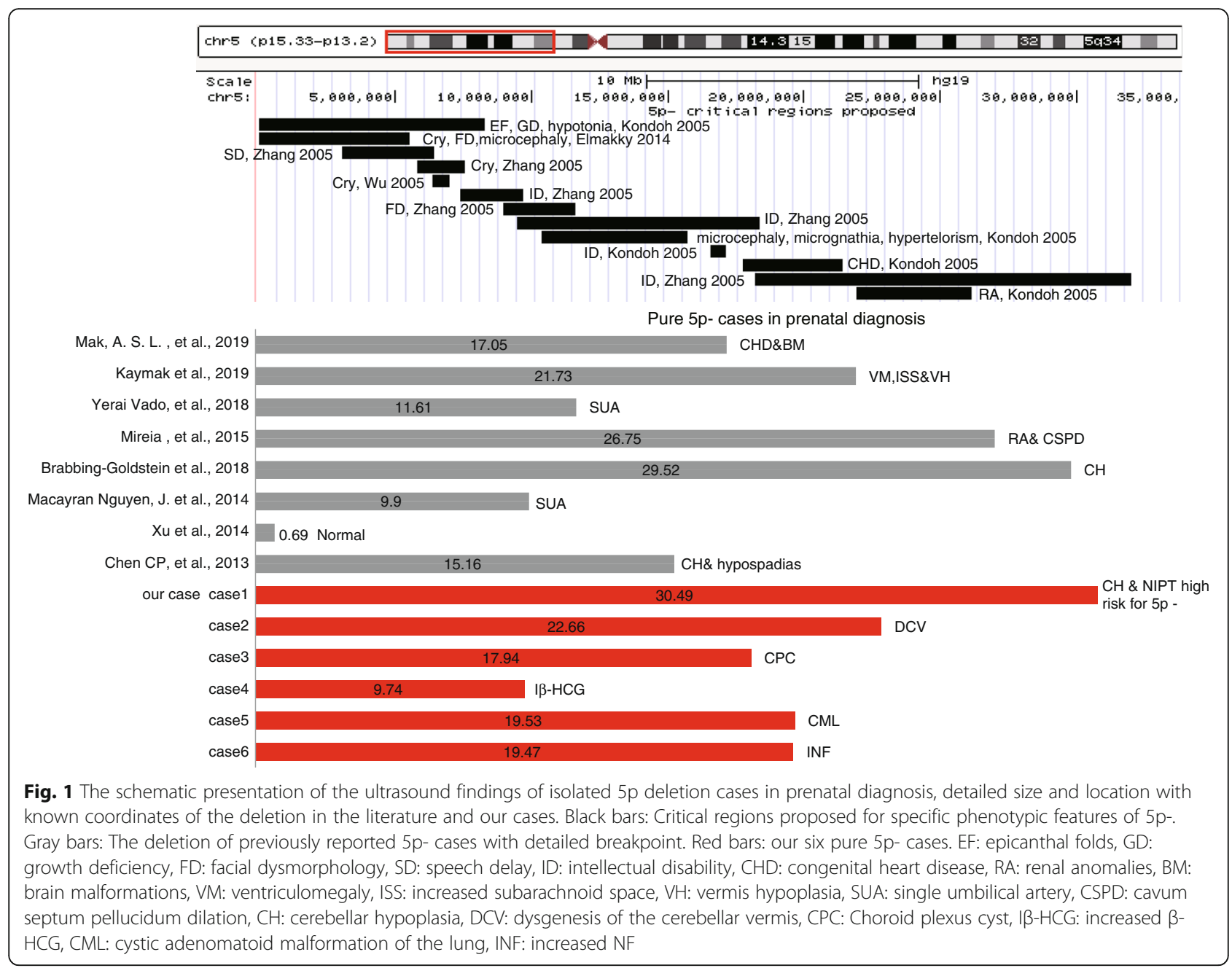

Table 2 Summary of the CdCS cases with pure terminal $5 p$ deletion from the literature compared to the 6 cases in our cohort $^{a}$

\begin{tabular}{llll}
\hline Prenatal ultrasound signs & Previously reported $(n=30)$ & Our group $(n=6))$ & $1 / 6$ \\
\hline Increased NT/NF & $2 / 30$ & $0 / 6$ & $3 / 36$ \\
IUGR & $1 / 30$ & $2 / 6$ & $1 / 36$ \\
Aplasia/Hypoplasia of the cerebellum & $7 / 30$ & $0 / 6$ & $9 / 36$ \\
Abnormality of the cerebral ventricles & $7 / 30$ & $0 / 6$ & $7 / 36$ \\
Absent/severely hypoplastic nasal bone & $2 / 30$ & $1 / 6$ & $2 / 36$ \\
Choroid plexus cyst & $4 / 30$ & $0 / 6$ & $5 / 36$ \\
Single umbilical artery & $4 / 30$ & $0 / 6$ & $4 / 36$ \\
VSD & $3 / 30$ & $0 / 6$ & $3 / 36$ \\
Hydrops fetalis & $3 / 30$ & $0 / 6$ & $3 / 36$ \\
Ascites & $3 / 30$ & $0 / 6$ & $3 / 36$ \\
Encephalocele & $1 / 30$ & & $1 / 36$ \\
Others & & $1 / 6$ & $8 / 36$ \\
Abnormal serum markers ( $\beta$-hCG, PAPP-A) & $7 / 30$ & $0 / 6$ \\
AMA without abnormal US finding & $3 / 30$ & $3 / 36$ \\
\hline
\end{tabular}

- ${ }^{2}$ Data collected from the 30 prenatal cases with pure distal $5 p$ deletion from 24 studies (Additional file 1: Table S1). IUGR Intrauterine growth retardation, VSD Ventricular septal defect, AMA Advanced maternal age, US Ultrasound. 
5 p15.2 include two pure 5p- cases (case 1,2) and three unbalanced translocation (case $8,9,11$ ) were found with cerebellar abnormalities, these data presented here indicated that cerebral abnormalities could probably become the most frequent prenatal feature of CdCS.

In previous prenatal studies, most of CdCS cases were diagnosed by routine G-banding karyotyping, which are observable only when the deletion size was larger than 5 $\mathrm{Mb}$ at the resolution approximately 400 bands. Eleven pure $5 \mathrm{p}$ - cases reported here with detail breakpoint without consistent features were observed (Fig.1). Multiple critical regions for the clinical feature were proposed, a $640 \mathrm{~kb}$ region at $5 \mathrm{p} 13$ and a $1.7 \mathrm{Mb}$ localized the $5 \mathrm{p} 15.31 \mathrm{p} 15.32$ region were characteristic for cat-like cry [30, 31]. Regions related with speech delay, mental retardation had been proposed as $3.2 \mathrm{Mb}$ in $5 \mathrm{p} 15.32$ $15.33,5 \mathrm{p} 15.2 \mathrm{p} 15.1$ with a $5.4 \mathrm{Mb} \sim 5.5 \mathrm{Mb}[7,32]$ and a $2.4 \mathrm{Mb}$ in $5 \mathrm{p} 15.2-15.31$ [31], respectively. Other facial dysmorphology features such as microcephaly, micrognathia, hypertelorism were reported in the $5.5 \mathrm{Mb}$ region by Kondoh et al. [32]. These critical region sizes were too small and beyond the G-band's resolution. Furthermore, some of $5 \mathrm{p}$ - syndrome cases might also be missed by conventional cytogenetic analysis alone [22]. Thus, combined CMA with karyotyping could be a definitive method for diagnosis of $5 \mathrm{p}$ - syndrome, and it can be expected that more cases of CdCS would be detected since routine clinical use of CMA in prenatal.

Determining the mechanism leading to the $5 \mathrm{p}$ - is essential for counseling and the recurrence risk estimation. Most of $5 p$ deletions were commonly de novo occurrences, about $80-90 \%$ of CdCS cases were results from terminal deletions, approximately $15 \%$ of CdCS had an unbalanced translocation, de novo or inherited. Other mechanisms include interstitial deletions (3-5\%), mosaicism (1.4\%), inversions $(0.5 \%)$, or ring chromosomes $(0.5 \%)[5,8]$. The molecular and cytogenetic tests of prenatal diagnosis in our state remains entirely patientsfunded, most of pregnant women with the $5 p$ deletion decided to termination of pregnancy directly without perform any further molecular tests based on consideration of the poor prognosis, we had no further information to evaluate the inheritance in these cases. This highlights the importance of genetic counseling for the families with high risk of translocation involving $5 p$ deletion, for the risk of producing a CdCS off-spring was estimated approximately 8.7 to $18.8 \%$ [4].

In summary, we presented the first largest prenatal series of CdCS diagnosed by SNP array in China. Though cerebellar abnormalities could be the most frequent features in prenatal CdCS cases, the prenatal ultrasound features of CdCS remain non-specific. When cases with ultrasound findings such as cerebellar abnormalities, absent/severely hypoplastic nasal bone, choroid plexus cyst, single umbilical artery, ventricular septal defect, hydrops fetalis, ascites, encephalocele are observed, a clinical suspicion of CdCS or other microdeletion/duplication syndromes should be considered. Combining typical karyotyping with CMA is a definitive method for a precise diagnosis of CdCS. Our findings expand the prenatal phenotypes of CdCS and highlight the importance of prenatal ultrasonography for the detection of chromosomal aberrations.

\section{Additional file}

Additional file 1: Table S1. Thirty-six prenatal cases with pure $5 p$ terminal deletions were reviewed from 24 published articles included our cases.

\section{Abbreviations}

AMA: Advanced maternal age; CdCS: Cri-du-chat syndrome; CLP: Cleft lip and palate; FTS: First trimester screening; IUGR: Intrauterine growth retardation; NIPT: Non-invasive prenatal testing; SNP array: Single nucleotide polymorphism array; US: Ultrasound; VSD: Ventricular septal defect; $\beta$ HCG: Beta-human chorionic gonadotropin

\section{Acknowledgments}

We thank the family for their support and all authors work in this study.

\section{Authors' contributions}

Wrote the manuscript: JSS, ZLQ. Conceived and designed the experiments: JSS, ZLQ. Performed the experiments: JSS, WLL, WL, BBX, SKW, YCL, QLC, TTJ and YW. JSS, WLL, WL, BBX were involved in SNP array analysis. JSL and QZ helped to revise the manuscript. All authors read and approved the final manuscript.

\section{Funding}

This work was supported in part by grants from the National Natural Science Foundation of China No. 81702919 and Guangxi Natural Science Foundation No. 2017JJB10161 and grants from Guangxi Zhuang Region Health Department No. Z2015234 and No. Z20190311.

Availability of data and materials

Please contact authors for data requests.

\section{Ethics approval and consent to participate}

written informed consent were obtained from the parents for publication of this report and any accompanying images. The consent form was approved by the ethical committee of Guangxi Maternal and Child Health Hospital, China.

\section{Consent for publication}

All patient in this report give their consent for images (such as face and clinical feature) or other clinical information relating to be reported for academic purpose.

\section{Competing interests}

The authors declare that they have no competing interests.

\section{Author details}

'Department of Genetic and Metabolic Central Laboratory, Guangxi Maternal and Child Health Hospital, Guangxi Birth Defects Prevention and Control Institute, No.59, Xiangzhu Road, Nanning, China. ${ }^{2}$ Department of Genetic Counseling, Guangxi Maternal and Child Health Hospital, No.225, Xinyang Road, Nanning, China. 
Received: 15 October 2019 Accepted: 27 November 2019

Published online: 09 December 2019

\section{References}

1. Lejeune, J., et al., 3 Cases of partial deletion of the short arm of a 5 chromosome]. (PMID: 14095841)

2. Nguyen $\mathrm{JM}$, et al. $5 p$ deletions: current knowledge and future directions. Am J Med Genet C Semin Med Genet. 2015;169(3):224-38.

3. Mainardi PC, et al. Clinical and molecular characterisation of 80 patients with 5p deletion: genotype-phenotype correlation. J Med Genet. 2001 38(3):151-8

4. Cerruti Mainardi P. Cri du chat syndrome. Orphanet J Rare Dis. 2006;1:33.

5. Mainardi PC, et al. The natural history of cri du chat syndrome. A report from the Italian register. Eur J Med Genet. 2006;49(5):363-83.

6. $\mathrm{Gu} \mathrm{H}$, et al. A familial cri-du-chat/5p deletion syndrome resulted from rare maternal complex chromosomal rearrangements (CCRs) and/or possible chromosome 5p chromothripsis. PLoS One. 2013:8(10):e76985.

7. Elmakky $A$, et al. A three-generation family with terminal microdeletion involving 5p15.33-32 due to a whole-arm 5;15 chromosomal translocation with a steady phenotype of atypical cri du chat syndrome. Eur J Med Genet. 2014:57(4):145-50.

8. Perfumo $\mathrm{C}$, et al. The first three mosaic cri du chat syndrome patients with two rearranged cell lines. J Med Genet. 2000;37(12):967-72.

9. Tullu MS, et al. Cri-du-chat syndrome: clinical profile and prenatal diagnosis. J Postgrad Med. 1998;44(4):101-4.

10. Fankhauser L, Brundler AM, Dahoun S. Cri-du-chat syndrome diagnosed by amniocentesis performed due to abnormal maternal serum test. Prenat Diagn. 1998;18(10):1099-100.

11. Aoki S, et al. Antenatal sonographic features of cri-du-chat syndrome. Ultrasound Obstet Gynecol. 1999;13(3):216-7.

12. Sherer DM, et al. Second-trimester diagnosis of cri du chat (5p-) syndrome following sonographic depiction of an absent fetal nasal bone. J Ultrasound Med. 2006;25(3):387-8

13. Teoh $\mathrm{XH}$, et al. Prenatal diagnosis of cri-du-chat syndrome: importance of ultrasonographical markers. Singapore Med J. 2009;50(5):e181-4.

14. Bakkum JN, et al. Prenatal diagnosis of cri du chat syndrome with encephalocele. Am J Perinatol. 2005;22(7):351-2.

15. Stefanou EG, et al. Prenatal diagnosis of cri du chat (5p-) syndrome in association with isolated moderate bilateral ventriculomegaly. Prenat Diagn. 2002;22(1):64-6.

16. Weiss $A$, et al. Prenatal diagnosis of $5 p$ deletion syndrome following abnormally low maternal serum human chorionic gonadotrophin. Prenat Diagn. 2003;23(7):572-4.

17. Li DZ, Yi CX. Prenatal diagnosis of cri du chat syndrome: four cases report. J Matern Fetal Neonatal Med. 2012;25(12):2799.

18. Chen $\mathrm{CP}$, et al. Cri-du-chat ( $5 \mathrm{p}$-) syndrome presenting with cerebellar hypoplasia and hypospadias: prenatal diagnosis and aCGH characterization using uncultured amniocytes. Gene. 2013;524(2):407-11.

19. Macayran Nguyen J, et al. Prenatal diagnosis of $5 p$ deletion syndrome in a female fetus leading to identification of the same diagnosis in her mother. Prenat Diagn. 2014;34(11):1115-8.

20. Han YJ, Kwak DW. Prenatal diagnosis of $5 p$ deletion syndrome: a case series report. J Gene Med. 2017:14(1):34-7.

21. Cardoso MC, et al. Prenatal sonographic diagnosis of isolated fetal ascites in cri-du-chat (5p-) syndrome: a case report. J Clin Ultrasound. 2019:47(4):232-4.

22. Mak ASL, et al. Prenatal diagnosis of $5 p$ deletion syndrome: report of five cases. J Obstet Gynaecol Res. 2019:45(4):923-6.

23. Kearney HM, et al. American College of Medical Genetics standards and guidelines for interpretation and reporting of postnatal constitutional copy number variants. Genet Med. 2011;13(7):680-5.

24. Steele MW. Letter: chromosome analysis of human amniotic-fluid cells. Lancet. 1974;2(7890):1210.

25. Higurashi $M$, et al. Livebirth prevalence and follow-up of malformation syndromes in 27,472 newborns. Brain Dev. 1990;12(6):770-3.

26. Liang $D$, et al. Clinical utility of noninvasive prenatal screening for expanded chromosome disease syndromes. Genet Med. 2019:21(9):1998-2006.

27. Advani HV, et al. Challenges in non-invasive prenatal screening for subchromosomal copy number variations using cell-free DNA. Prenat Diagn. 2017;37(11):1067-75.
28. Wang J, et al. Lower detectability of non-invasive prenatal testing compared to prenatal diagnosis in high-risk pregnant women. Ann Transl Med. 2019; 7(14):319.

29. Simmons $A D$, et al. Five novel genes from the cri-du-chat critical region isolated by direct selection. Hum Mol Genet. 1995;4(2):295-302.

30. $W u Q$, et al. Determination of the 'critical region' for cat-like cry of cri-duchat syndrome and analysis of candidate genes by quantitative PCR. Eur J Hum Genet. 2005;13(4):475-85.

31. Zhang $X$, et al. High-resolution mapping of genotype-phenotype relationships in cri du chat syndrome using array comparative genomic hybridization. Am J Hum Genet. 2005;76(2):312-26.

32. Kondoh T, et al. Genotype-phenotype correlation of 5p-syndrome: pitfall of diagnosis. J Hum Genet. 2005;50(1):26-9.

\section{Publisher's Note}

Springer Nature remains neutral with regard to jurisdictional claims in published maps and institutional affiliations.
Ready to submit your research? Choose BMC and benefit from:

- fast, convenient online submission

- thorough peer review by experienced researchers in your field

- rapid publication on acceptance

- support for research data, including large and complex data types

- gold Open Access which fosters wider collaboration and increased citations

- maximum visibility for your research: over $100 \mathrm{M}$ website views per year

At BMC, research is always in progress.

Learn more biomedcentral.com/submissions 